\title{
Design Guidelines for Creating a Convincing User Experience with Virtual In-vehicle Assistants
}

\author{
Timo Strohmann \\ University of Braunschweig \\ t.strohmann@tu-bs.de
}

\author{
Laura Höper \\ University of Braunschweig \\ laura.hoeper@tu-bs.de
}

\author{
Susanne Robra-Bissantz \\ University of Braunschweig \\ s.robra-bissantz@tu-bs.de
}

\begin{abstract}
This research provides guidelines for the representational and interaction design of virtual invehicle assistants. The guidelines offer a clearly structured overview about what designers have to consider while creating in-vehicle virtual assistants with a convincing user experience. The design guidelines are developed using the design science research methodology. Based on assistant requirements for a great user experience derived from the previous research literature and the results of five expert interviews, concrete guidelines for the design of invehicle virtual assistants are developed. For evaluation, the guidelines are presented to another expert and then refined based on her feedback.
\end{abstract}

\section{Introduction}

An increasing number of people use virtual assistants (VAs) in their everyday life [9]. These intelligent software programs support users with various concerns while interacting with them in a seemingly natural and human-like way [23]. To give some examples, APPLE's SIRI, GOOGLE's GOOGLE Now and MiCROSOFT'S CORTANA are specialized for the use on mobile phones while VAs like AMAZON ECHO and GOOGLE HOME are optimized for fulfilling tasks in smart homes [18].

Because of the fast growth in the areas of artificial intelligence and information technology, user assistance is about to become way more intelligent [13]. While user assistance in the past was more about helping functions in textual form, personal assistants on our smartphones mentioned before, can process natural language and react in a human way [13, 23]. With growing artificial intelligence technology, machines may even be found in collaborative settings with humans in the future, which might change the way we work with information technology fundamentally [22].
Therefore, research is needed, giving a guiding function for the design of virtual user assistance.

In the automotive context there has already been research concerning assistance systems for proactively supporting the driver in the past 30 years [1]. But a research approach for user assistance in the form of a virtual in-vehicle assistant is still missing. Designing a voice user interface (VUI), especially for in-vehicle use, implies additional challenges compared to mobile phone or home assistants [18]. While driving a car, users have special needs, desires and pains. To provide a convincing user experience (UX), the assistant's character, the way of handling the system and the functions have to be tailored to the context of a vehicle [18].

To address this challenge, there is a lack of wellformulated and structured design guidelines specifically for in-vehicle assistants. The aim of this research is to develop design guidelines for in-vehicle VAs that focus on two design activities: Representational design and interaction design. According to BENYON, representational design deals with the style, aesthetics and the overall look and feel of the system [2]. The interaction design determines how functions will be allocated to the user and the machine and how the interaction between user and machine will take place [2]. Representational and interaction design are selected because they have a significant impact on how users will perceive the system, how easy and enjoyable it will be to use and therefore on the overall UX [2].

The guidelines were developed following the design science research (DSR) methodology and are based on prior research in the field as well as on qualitative expert interviews. To bridge academic research and industry practice, primarily experts from the automotive sector are chosen who work on the design and development of in-vehicle assistance.

In this paper we address the research question: How to design a virtual in-vehicle assistant providing a convincing UX regarding representational and interaction design?

The paper is structured as follows: First, we give some insights about the theoretical background on UX 
and VAs. Afterwards, our research approach is described and our proposed guidelines are presented. Lastly, we are discussing our results considering limitations and possible future work.

\section{Theoretical Background}

\subsection{Criteria for a convincing $U X$}

The ISO standard defines UX as “a person's perceptions and responses that result from the use or anticipated use of a product, system or service" [24]. The UX is tightly correlated to the usability as the usability defines how easy to learn, how effective to use and how enjoyable a product is [20].

To create a good usability, designers often refer to NIELSEN AND MOLICH who developed ten usability heuristics for designing graphical user interfaces (GUIs) in 1990 [16]. According to ZHOU AND FU, not only the usability but also the hedonic aspects of a product can have a significant influence on the UX [26]. HASSENZAHL confirms this statement by arguing that a product has to provide both a set of functional features and an experience to convince the user [7]. Emotions and affects are integral aspects of such an experience [8]. As ScHMiTT describes, customers want products to "dazzle their senses, touch their hearts, and stimulate their minds" [21]. This comprehensive concept of a convincing UX, depending not only on the pragmatic usability but also on hedonic aspects of a product, should be considered during the design process.

\subsection{Design Principles for VAs}

VAs are software programs fulfilling tasks and answering questions for their users [25]. Therefore, they are able to process natural language and interact in a human-like way, following social norms of interpersonal communication $[6,23,25]$.

As voice-based VAs are becoming mainstream [18], researchers have published an increasing number of scientific work dealing with the principles and process of designing a VUI in recent years. For example, COHEN ET AL. give advice for the design of interactive voice response systems which is an early form of VAs that became common in 2000 and helped the caller via telephone with various concerns [3]. PEARL learned from the findings of COHEN ET AL. and transferred them to voice-enabled mobile phone apps like SIRI, GOOGLE Now, Hound and CORTANA, which did not yet exist in 2004 [18]. She gives advice on what to consider when it comes to the design of VUIs and was able to include statements, tips and best practices from other experts like IAN MENZIES, senior voice UX designer at LAB126 (AMAZON) [18].

PEARL mentions some new requirements and challenges that occur when designing VUIs for cars [18]. For instance, she explains that minimizing the user's cognitive load is especially important for the design of in-vehicle assistants because the conversation with the VA must not distract the driver while focusing on the road and traffic [18]. What the literature does not submit are concrete guidelines with all the specifics to be considered in order to build VAs providing a convincing UX especially in a vehicle.

\section{Research Approach}

The approach of this research is based on the DSR methodology. According to PEFFERS ET AL., the goal of DSR is to develop an artifact that provides a solution for a comprehended research problem [19]. Such an artifact can be for example a construct, model, method, instantiation or social innovation [19]. In this case, the artifact are the design guidelines for virtual in-vehicle assistants.

\subsection{Expert Interviews}

When it comes to the design and development of the guidelines, it makes sense to learn from existing research literature dealing with creating a convincing UX and what to consider while designing VUIs. The review of previous findings yields some requirements for VAs in order to provide a convincing UX. As the literature has barely dealt with the design of specifically in-vehicle assistants so far, primarily general assistant requirements can be derived from the research literature.

To examine the validity of the derived assistant requirements especially for in-vehicle assistants and to generate concrete guidelines for the design, five expert interviews are conducted. An interview guide for the semi-structured expert interviews is created based on the assistant requirements derived from literature research. The interview guide includes a number of questions that serve to examine if the derived assistant requirements are valid especially for in-vehicle assistants or if they have to be changed or extended. In addition to that, the interview guide contains questions that address how the derived assistant requirements from literature can be implemented into concrete design. The last question offers the opportunity for the interviewee to mention additional assistant requirements or design implications that are not covered in literature or not considered so far.

3.1.1. Expert Interview Participants. With the selection of the five interviewees it is considered that not 
only the design but also the psychological and technological perspectives on the design of in-vehicle assistants is covered. EXPERT 1 is a psychologist who is concerned with the human-machine interaction especially in vehicles. EXPERT 2 also dealt a lot with psychological topics during his studies, but in comparison to EXPERT 1, he has a more technological background as he earned his $\mathrm{PhD}$ in automotive engineering. EXPERT 3 is an electrical engineer working for a software development company in the automotive sector where he is appointed as a project manager for the research and advanced development of speech assistants. EXPERT 4 deals with the holistic UX in the vehicle and coordinates UX design workshops for a VA. As this research is conducted in the context of an automotive company, the experts are mainly part of different projects that deal with the design and development of VAs in and around the vehicle. To prevent bias, an independent machine learning and speech recognition researcher is interviewed as expert as well (EXPERT 5).

3.1.2. Expert Interview Analysis. The expert interviews are recorded with an audio recorder to capture all the details in order to transcribe them subsequently. The analysis of the expert interviews is based on MEUSER AND NAGEL's approach: after the transcription, thematically relevant passages of the transcribed interviews are paraphrased [10]. For the next step, the descriptive coding approach is used. As MILES ET AL. explain, a descriptive code labels a unit of qualitative data with one word or phrase that summarizes the main topic of this passage [11]. The applied codes are created inductively meaning that they emerge progressively during data collection [11]. The coding was conducted by two of the authors separately and discussed and aggregated after each coding cycle. In summon 40 codes grouped into 15 categories evolved during the coding session. After coding, a thematic comparison summarizes the experts statements and links thematically comparable passages from the different interviews [10]. Commonly shared expert knowledge regarding the particular topics is condensed and interrelated with the academic discourse. Relating the expert interview results to the findings from literature research yields that all the assistant requirements providing a convincing UX derived from the previous literature are true and relevant for invehicle VAs. A few requirements are extended and some additional requirements are added.

\subsection{Development of Design Guidelines}

Based on the assistant requirements derived from literature and the expert interviews, concrete design guidelines for virtual in-vehicle assistants are developed that will help designers to fulfill the assistant requirements and therefore provide a convincing UX with the implemented VA. For evaluation, the design guidelines are presented to a further expert (EXPERT 6) who works for a large German automaker where she is involved in the UX design for different VA projects. Having a lot of practical experience with designing VAs, the expert is asked to suggest improvements and to add missing design guidelines. Her feedback is used to evaluate the artifact. After the evaluation, the design guidelines are refined with the new insights following the iterative DSR methodology by PEFFERS ET AL. [19]. Due to the limited scope of this scientific work, the guidelines are evaluated and refined once. In further research, the guidelines may be evaluated through a specific implementation of a VA, which is designed according to the proposed guidelines.

\section{Results}

The following section presents the evaluated and refined guidelines for the representational and interaction design of virtual in-vehicle assistants. To provide a clearly structured overview, the guidelines were clustered in four thematically related blocks. While Table 1 focuses on the representational design of a VA,Table 2, Table 3 and Table 4 deal with the design of the interaction between user and VA. The tables regarding interaction design are divided in design guidelines for intuitive conversation (Table 2), simple operation (Table 3) and appropriate behavior (Table 4). All of the four tables give an overview about the assistant requirements for a convincing UX that are derived not only from the existing research literature but also from the expert interviews. Moreover, they present the evaluated design guidelines for in-vehicle assistants that will help designers to fulfill the assistant requirements and to provide a convincing UX. To simplify using the guidelines in practice, some guidelines have been prioritized based on the findings of the expert interview analysis. The guidelines that should be emphasized by practitioners are highlighted in bold in Table 1-4.

There are two requirements that have particular salience for in-vehicle assistants compared to assistants in other contexts: Requirement 7 refers to the reduction of the user's cognitive load, which is especially important for in-vehicle use. In addition to that, requirement 13 aims on a proactive behavior. The experts suggest various vehicle-specific use cases where proactivity can vastly increase the user experience with a VA in a vehicle. For example, according to EXPERT 5, it would be pleasant for the user if the VA would 
propose an alternative route timely before the user gets stuck in a traffic jam. EXPERT 2 suggests that, if the VA would have access to the technical vehicle data, it could proactively premonish the user if something needs his attention. To conclude, compared to designing virtual assistants for other contexts, designers should particularly focus on the guidelines 7.1.-7.4. and 13.113.4 when designing assistants for in-vehicle use.

\subsection{Guidelines for Representational Design}

4.1.1. Personality and Background Story. As shown in Table 1, PEARL and COHEN ET AL. point out that a VA needs a consistent personality and a background story to provide a convincing UX $[3,18]$. All the experts support that the UX can be improved if a VA has a personality because this enables building emotional rapport with the user, provides hedonic, playful and surprising aspects and makes the VA more fun to use. To ensure consistency, it helps to create a persona for the VA including name, background story and personality traits that can be considered during the whole design process. For the background story, EXPERT 2 and 4 recommend that designers should not try to imitate a humane biographical sketch but rather integrate fictional descriptions. When it comes to the definition of personality traits, none of the experts is able to describe an ideal personality of a VA, because it depends on the preferences of the particular user. According to EXPERT 2, comprehensive user research can help to tailor the personality to the target customers. It would be even better, if the personality would fit to the individual user and his mood in a certain situation by evolving certain personality traits over time, based on the user's interactions. In this case, predefined borders are helpful to ensure that the character still represents the brand values.

4.1.2. Voice and Linguistic Register. Another aspect that has a great influence on the VA's look and feel is its voice and linguistic register. COHEN ET AL. are convinced that "[w]hatever you decide in terms of the most appropriate register for your application, make sure that it's exercised consistently throughout your dialog" [3]. All the experts are convinced that when designing the linguistic register, designers should take advantage of the conversational norms users are already familiar with in order to let the conversation appear more natural. A rather informal everyday language is appropriate but it has to be ensured that the VA still represents the brand image. For a convincing UX, it makes sense to reflect the user's word choice in the utterances of the VA. Nevertheless, EXPERT 6 warns that designers have to take care of words the VA should not adopt by letting somebody manually approve which expressions the VA learns (filtering).

4.1.3. Visual Appearance and Humanity. According to PEARL, it is an important design decision whether a VA should have a visual representation [18]. EXPERT 2, 3 and 4 recommend to design some kind of visualization because the user needs something to turn towards while speaking and because it can be used to give visual feedback. By clarifying the different modes of the system (e.g. VA is listening), visual feedback can help the user to handle the interaction and to understand the system.

The experts also give the advice to not use an avatar or a human-like visualization but something more abstract like a flickering light. This advice refers to a concept which is known as the uncanny valley invented by MASAHIRO MORI in the 1970s. MORI says that it will make people feel eerie and as if they would have been fooled when a robot appears very human-like but in the end turns out not to be a real human [14]. This is why EXPERT 2 points out that it should be communicated honestly that the VA is not a human. To avoid raising false expectations, it is also important to communicate that the VA is just a machine with a limited range of functions. If something is out of its domain, the VA should clearly remain that it is not able to help with this topic.

While evaluating the guidelines, EXPERT 6 suggests to let the VA show human errors and idiosyncrasies while talking because this can make the conversation appear more natural and the VA more lovable. Here it has to be considered that if the VA would make mistakes in terms of delivering wrong content or conducting the wrong function, it would rather cause mistrust in the system.

Table 1: Design guidelines for representational design

\begin{tabular}{|c|c|c|c|}
\hline $\begin{array}{l}\text { Assistant } \\
\text { requirements }\end{array}$ & $\begin{array}{l}\text { Supporting } \\
\text { literature }\end{array}$ & Design guidelines for in-vehicle VAs & Experts \\
\hline $\begin{array}{l}\text { 1. An in-vehicle } \\
\text { VA needs a } \\
\text { consistent }\end{array}$ & $\begin{array}{l}\text { PEARL } \\
{[18: 72]} \\
\text { COHEN ET }\end{array}$ & $\begin{array}{l}\text { 1.1. Create a persona for the VA (name, background, } \\
\text { personality) and use it as a style guide during the whole design } \\
\text { process. }\end{array}$ & E $1-5$ \\
\hline $\begin{array}{l}\text { personality and a } \\
\text { background story. }\end{array}$ & $\begin{array}{l}\text { AL. }[3: 78] \\
{[3: 82]}\end{array}$ & $\begin{array}{l}\text { 1.2. Do not try to imitate a humane biography with the VA's } \\
\text { background story but rather integrate fictional descriptions. }\end{array}$ & E 2,4 \\
\hline
\end{tabular}




\begin{tabular}{|c|c|c|c|}
\hline \multirow{8}{*}{$\begin{array}{l}\text { 2. An in-vehicle } \\
\text { VA has to use a } \\
\text { consistent voice } \\
\text { and linguistic } \\
\text { register. }\end{array}$} & & $\begin{array}{l}\text { 1.3. Predetermine one or a few personalities based on user } \\
\text { research results and brand values. }\end{array}$ & E 2-4 \\
\hline & & $\begin{array}{l}\text { 1.4. Let the VA evolve some character traits more than others } \\
\text { within predefined borders dependent on the interaction with the } \\
\text { user. }\end{array}$ & E 1 \\
\hline & \multirow{6}{*}{$\begin{array}{l}\text { COHEN ET } \\
\text { AL. } \\
{[3: 163]}\end{array}$} & $\begin{array}{l}\text { 2.1. Decide if the VA should have a default voice or if the user } \\
\text { should have the choice between a range of different voices. }\end{array}$ & E $1-3$ \\
\hline & & $\begin{array}{l}\text { 2.2. Take care that different voices also imply different } \\
\text { personalities. }\end{array}$ & E 6 \\
\hline & & 2.3. Use conversational norms that are familiar to the user. & E $1-5$ \\
\hline & & $\begin{array}{l}\text { 2.4. Use casual and informal everyday language but ensure that } \\
\text { the VA still represents the brand image. }\end{array}$ & E 1,4 \\
\hline & & $\begin{array}{l}\text { 2.5. Reflect the user's word choice in the utterances of the VA } \\
\text { (with filtering). }\end{array}$ & $\begin{array}{l}\text { E } 1-2, \\
4,6\end{array}$ \\
\hline & & $\begin{array}{l}\text { 2.6. Allow the human way of evolving a different conversation } \\
\text { style and register after some time when getting to know each other } \\
\text { better. }\end{array}$ & E 6 \\
\hline \multirow{2}{*}{$\begin{array}{l}\text { 3. An in-vehicle } \\
\text { VA needs a visual } \\
\text { representation. }\end{array}$} & \multirow{2}{*}{$\begin{array}{l}\text { PEARL } \\
{[18: 71]}\end{array}$} & 3.1. Use an abstract, not a human-like visualization of the VA. & E 2-4 \\
\hline & & 3.2. Give visual feedback. & E 3-4 \\
\hline \multirow{3}{*}{$\begin{array}{l}\text { 4. An in-vehicle } \\
\text { VA should not } \\
\text { pretend to be a } \\
\text { human. }\end{array}$} & & 4.1. Communicate honestly that the VA is not a human. & E 2 \\
\hline & & 4.2. Be transparent about the limitations of the VA. & E 6 \\
\hline & & $\begin{array}{l}\text { 4.3. Integrate human errors and idiosyncrasies regarding how the } \\
\text { VA talks but not regarding content or functions. }\end{array}$ & $\mathrm{E} 2,6$ \\
\hline
\end{tabular}

\subsection{Guidelines for Interaction Design}

4.2.1. Detecting Voice Interaction. As Table 2 shows, an important design decision is how the in-vehicle assistant knows when to listen and react to the user [18]. Most of today's voice assistants require the users explicitly indicating when they want to speak to the system, for example, by using a push-to-talk button or a wake word [18]. Researchers are trying to figure out new methods that are more oriented towards interpersonal interaction behavior. As EXPERT 2, 3 and 4 explain, people indicate to whom they are talking, for example, by looking at the person they are addressing, by calling a name or the addressee simply derives it from the content of what is said. They propose that, at best, the VA makes use of these conventions as well and calculates the likelihood that it is addressed in a certain situation by combining various information.

4.2.2. Navigation within the Conversation. There is one point where every expert has the same opinion: The goal is to design the VA in such a way that the interaction with it is like interpersonal communication, as natural and intuitive as possible. For a simple navigation within the conversation the functions undo, repeat, help and stop have to be integrated. To create a convincing UX, it would be ideal if the VA not only understands short commands but also a more natural way of instructing the VA to perform one of the mentioned functions. As EXPERT 6 points out during her evaluation, the conversation should not be based on a static dialog flow but on more flexible dialogs that allow the users to access the conversation at any point.

4.2.3. Minimizing Cognitive Load. Table 3 summarizes the guidelines to design the operation and control of the system for the user as simple as possible. Especially in the car, it is crucial to hold down the user's cognitive load to avoid distracted driving [18]. EXPERT 5 argues that the more activities the VA can accomplish for the user, the less will they distract him from his actual task which is driving the car. Nevertheless, listening and speaking still adds cognitive distraction [18]. This is why messages of the VA have to be crisp and clear and focused on the most important information [18]. In order to not overwhelm the user while communicating with a VA, it makes sense to break down information and processes into small pieces and to provide next steps sequentially [12]. Trying to explain complex information through the VUI makes it still unnecessarily complicated for the user. In such situations, EXPERT 4 recommends to show additional visual feedback on the car's infotainment screen to clarify the VA's utterances. Nevertheless, designers should try to use the GUI while driving as less as possible to avoid creating distraction for the driver [18]. 
Table 2: Design guidelines for interaction design: Intuitive conversation

\begin{tabular}{|c|c|c|c|}
\hline $\begin{array}{l}\text { Assistant } \\
\text { requirements }\end{array}$ & $\begin{array}{l}\text { Supporting } \\
\text { literature }\end{array}$ & Design guidelines for in-vehicle VAs & Experts \\
\hline \multirow{3}{*}{$\begin{array}{l}\text { 5. An in-vehicle } \\
\text { VA has to detect } \\
\text { when it is } \\
\text { addressed. }\end{array}$} & \multirow[t]{3}{*}{$\begin{array}{l}\text { PEARL } \\
{[18: 152]}\end{array}$} & $\begin{array}{l}\text { 5.1. Learn from interpersonal communication how people } \\
\text { indicate conversations and transfer patterns to the human- } \\
\text { machine interaction. }\end{array}$ & E 2-4 \\
\hline & & $\begin{array}{l}\text { 5.2. Collect information to calculate how likely it is that the VA } \\
\text { is addressed in a certain situation. }\end{array}$ & E 3 \\
\hline & & $\begin{array}{l}\text { 5.3. Be transparent about the functionality of active listening and } \\
\text { observing and enable the user to shut the system off completely. }\end{array}$ & E 6 \\
\hline \multirow{4}{*}{$\begin{array}{l}\text { 6. An in-vehicle } \\
\text { VA has to enable } \\
\text { intuitive } \\
\text { conversation. }\end{array}$} & \multirow{4}{*}{$\begin{array}{l}\text { NIELSEN } \\
{[16]} \\
\text { PEARL } \\
{[18: 226]}\end{array}$} & $\begin{array}{l}\text { 6.1. Learn from interpersonal communication to design the } \\
\text { interaction as natural and intuitive as possible. }\end{array}$ & E $1-6$ \\
\hline & & 6.2. Integrate at least the functions undo, repeat, help and stop. & E 3 \\
\hline & & $\begin{array}{l}\text { 6.3. Not only let the VA understand short commands but also } \\
\text { a more natural way of saying something. }\end{array}$ & $\begin{array}{l}\text { E } 2-3, \\
5\end{array}$ \\
\hline & & $\begin{array}{l}\text { 6.4. Design flexible dialogs that allow the user to access the } \\
\text { conversation at any point. }\end{array}$ & E 6 \\
\hline
\end{tabular}

4.2.4. Providing Help. In general, it is not necessarily obvious for the user what a VA can do and which voice commands it understands because the functionalities are not shown on a screen [4]. Therefore, VAs have to be able to inform the users about this [12]. Adverting to an app or a website that informs about possible services and functions might be a good solution but according to EXPERT 6 the in-vehicle VA also has to have this information available if the user asks for it.

As EXPERT 6 adds, setting the expectations about the VA's functionalities in the onboarding process can help the user to get an overview about what to ask for. In addition to that, EXPERT 1 recommends that the VA can proactively inform the user about certain functions that he did not use before, if this is something that fits to the current situation. Not only COHEN ET AL. but also EXPERT 2 suggests that the VA should give just-in-time instructions for the imminent activity if needed [3]. Here it is important to not exaggerate and permanently teach the user how to answer because in the best case, the user should be able to answer intuitively [5].

4.2.5. Feedback and System Familiarity. As presented in Table 3, one of the requirements for a convincing UX is that the system gives appropriate feedback within reasonable time to keep the users informed [16]. Designers have to define how much feedback the VA should give about what it understands and about its actions [18]. The possibilities range from explicitly asking the user for his permission, to only letting him know what the VA recognized by repeating what the user said, to just doing it without revealing what has been understood [18]. EXPERT 2 emphasizes that even if the VA gives no feedback it still has to be able to explain what it did and why it did this if the user asks for it.

According to EXPERT 2 and 3, which kind of feedback is appropriate in a certain situation depends on how confident the VA is that it understood correctly and how critical a mistake and its consequences would be. Another factor that has an influence on how much feedback the VA should give is how familiar the user already is with the system. EXPERT 2 is sure that it makes sense to let the VA give less and less feedback over time for functions that are used on a regular basis. In general, EXPERT 1-5 argue that an in-vehicle VA should provide more explanations for novice users and reduce the amount and extent step by step. Nevertheless, EXPERT 6 explains that if people do not trust the system, they might want the VA to tell them exactly what the VA understood and what it did although they are already familiar with the system. In such case, the VA has to figure out this personal preference in order to behave appropriately.

4.2.6. Error Handling. Designers have to develop a good strategy of handling errors because preventing them completely is not possible [18]. First of all, how EXPERT 3, 4 and 5 point out, it is very important that the system recognizes that it understood something wrong or that something is out of its domain to avoid undesired actions. However, repeatedly admitting "Sorry, I don't understand" also would not appear smart. EXPERT 1 suggests that, if the VA at least understands parts of what the user said, it can react to this and give feedback about what it did not understand by using a simple request. After all, if the VA repeatedly does not 
understand what the user is saying or if it recognizes that it is not able to help the user with a certain problem because it is something that is out of its domain, EXPERT 3 suggests that it might be an option to transfer the user to a human customer service agent. Another use case, where it makes sense to automatically call a human agent, is an emergency situation such as an accident.

Table 3: Design guidelines for interaction design: Simple operation

\begin{tabular}{|c|c|c|c|}
\hline $\begin{array}{l}\text { Assistant } \\
\text { requirements }\end{array}$ & $\begin{array}{l}\text { Supporting } \\
\text { literature }\end{array}$ & Design guidelines for in-vehicle VAs & Experts \\
\hline \multirow{4}{*}{$\begin{array}{l}\text { 7. An in-vehicle } \\
\text { VA has to } \\
\text { minimize the } \\
\text { user's cognitive } \\
\text { load. }\end{array}$} & \multirow{4}{*}{$\begin{array}{l}\text { PEARL } \\
{[18: 226]} \\
\text { COHEN ET } \\
\text { AL. [3:119] } \\
\text { MOORE ET } \\
\text { AL. [12:5] }\end{array}$} & $\begin{array}{l}\text { 7.1. Let the VA accomplish as much activities for the user as } \\
\text { possible. }\end{array}$ & E 5 \\
\hline & & $\begin{array}{l}\text { 7.2. Formulate the VA's sentences crisp and clear and focus on } \\
\text { important information. }\end{array}$ & E 4 \\
\hline & & $\begin{array}{l}\text { 7.3. Break down information and processes into small pieces and } \\
\text { provide next steps sequentially. }\end{array}$ & E 4 \\
\hline & & $\begin{array}{l}\text { 7.4. Be aware of the situational context to choose the best way to } \\
\text { provide content (VUI or GUI). }\end{array}$ & $\mathrm{E} 2,4$ \\
\hline \multirow{4}{*}{$\begin{array}{l}\text { 8. An in-vehicle } \\
\text { assistant has to be } \\
\text { able to inform the } \\
\text { user about what it } \\
\text { can do. }\end{array}$} & \multirow{4}{*}{$\begin{array}{l}\text { PEARL } \\
\text { [18:65] } \\
\text { COHEN ET } \\
\text { AL. [3:127] } \\
\text { MOORE ET } \\
\text { AL. [12:5] } \\
\text { CRAMER } \\
\text { AND THOM } \\
\text { [4:3] }\end{array}$} & $\begin{array}{l}\text { 8.1. Create an additional app or a website to inform about } \\
\text { functionalities but also allow the VA to have this information } \\
\text { available. }\end{array}$ & E 6 \\
\hline & & $\begin{array}{l}\text { 8.2. Set expectations about functionalities in the onboarding } \\
\text { process. }\end{array}$ & E 6 \\
\hline & & $\begin{array}{l}\text { 8.3. Inform the user proactively about certain unused functions } \\
\text { tailored to the current situation. }\end{array}$ & E 1 \\
\hline & & $\begin{array}{l}\text { 8.4. Let the VA give just-in-time instructions for the imminent } \\
\text { activity if needed but do not permanently teach the user how to } \\
\text { answer. }\end{array}$ & E 2 \\
\hline \multirow{4}{*}{$\begin{array}{l}\text { 9. An in-vehicle } \\
\text { VA has to give } \\
\text { appropriate } \\
\text { feedback within } \\
\text { reasonable time. }\end{array}$} & \multirow{4}{*}{$\begin{array}{l}\text { PEARL } \\
{[18: 144]} \\
{[18: 226]} \\
\text { NIELSEN } \\
{[16]}\end{array}$} & $\begin{array}{l}\text { 9.1. Define how much feedback the VA should give about what it } \\
\text { understands and does. }\end{array}$ & E 2-3 \\
\hline & & 9.2. Define if and how the user should confirm the VA's actions. & E 3 \\
\hline & & $\begin{array}{l}\text { 9.3. Decide which kind of feedback is appropriate based on } \\
\text { how confident the VA is that it understood correctly, how } \\
\text { critical a mistake and its consequences would be and how } \\
\text { familiar the user is with the system. }\end{array}$ & E 2-4 \\
\hline & & $\begin{array}{l}\text { 9.4. Take care that the VA is always able to be transparent about } \\
\text { what it did and why it did it. }\end{array}$ & E 2 \\
\hline \multirow{3}{*}{$\begin{array}{l}\text { 10. An in-vehicle } \\
\text { VA has to tailor } \\
\text { the interaction } \\
\text { style to the user's } \\
\text { familiarity. }\end{array}$} & \multirow{3}{*}{$\begin{array}{l}\text { PEARL } \\
{[18: 47]} \\
\text { NIELSEN } \\
{[16]} \\
\text { COHEN ET } \\
\text { AL. }[3: 207]\end{array}$} & $\begin{array}{l}\text { 10.1. Let the VA change the way of giving feedback over time } \\
\text { for functions that the user is already familiar with. }\end{array}$ & E 2-4 \\
\hline & & $\begin{array}{l}\text { 10.2. Provide more explanations for novice users and reduce } \\
\text { the amount and extent step by step. }\end{array}$ & E $1-5$ \\
\hline & & $\begin{array}{l}\text { 10.3. Let the VA detect how trustful the user is towards the system } \\
\text { to be able to adjust its interaction style to the user's trust level. }\end{array}$ & E 6 \\
\hline \multirow{3}{*}{$\begin{array}{l}\text { 11. An in-vehicle } \\
\text { VA has to } \\
\text { prevent errors but } \\
\text { in case also needs } \\
\text { a good strategy of } \\
\text { handling them. }\end{array}$} & \multirow{3}{*}{$\begin{array}{l}\text { PEARL } \\
{[18: 41]} \\
\text { NIELSEN } \\
{[16]} \\
\text { COHEN ET } \\
\text { AL. }[3: 228]\end{array}$} & $\begin{array}{l}\text { 11.1. Try to prevent errors as much as possible but also create a } \\
\text { good strategy for handling the errors if they occur. }\end{array}$ & E $1-2$ \\
\hline & & $\begin{array}{l}\text { 11.2. Make sure that the system recognizes that it understood } \\
\text { wrong or that something is out of its domain to avoid } \\
\text { undesired actions. }\end{array}$ & E $3-5$ \\
\hline & & $\begin{array}{l}\text { 11.3. Create charming responses for the case that something is out } \\
\text { of the VA's domain. }\end{array}$ & E 2 \\
\hline
\end{tabular}




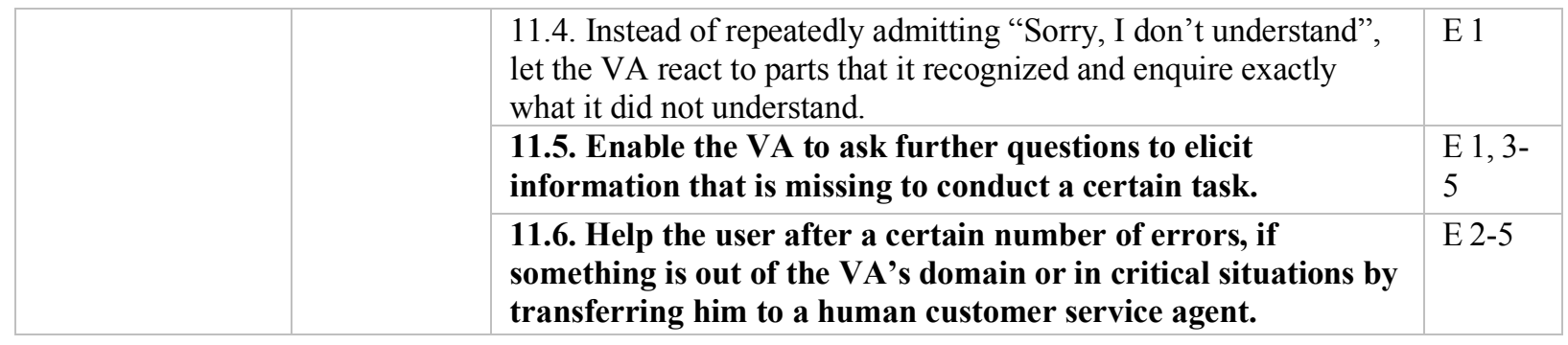

4.2.7. Emotions and Empathy. As described in section 2.1., a product has to provide both a set of functional features and an experience to convince the user [8]. Emotions and moods influence how people experience situations and how they interact in them [15]. A VA can recognize the user's emotions by analyzing gestures, facial expressions, text, tone of voice and physiological signs of mood such as heart rate or skin changes [17].

To convey the image of an emotionally intelligent assistant, a VA not only has to detect the user's emotions and mood but also has to react to them appropriately [17]. EXPERT 1 suggests to let the VA tailor its communication style and the content of what it says to the user's mood and to possible pains in the current situation. Another way to react to the detected emotional state of the user would be that the VA itself shows emotions. EXPERT 1-4 warn designers to take care that while showing emotions, the VA still has to focus on assisting the user and that it does not behave inappropriate, ridiculous or strange. EXPERT 1 clarifies that it depends on the situation and on the individual user and his mood if showing emotions has a positive or rather a negative effect. This is why EXPERT 6 recommends to preset how emotional the VA should be in general but to allow flexible adjustment in some extent.

4.2.8. Proactivity. EXPERT 5 is sure that the UX can be increased if a virtual in-vehicle assistant tells the user something proactively making his life easier or preventing him from unpleasant situations. In some situations, proactively addressing the user can even improve the driving safety. For instance, EXPERT 3 suggests that if the user is not concentrated on the road and there is a critical traffic situation in front of him, the VA can warn him to prevent a possible accident. Especially during long travels, an in-vehicle assistant can help keeping the driver awake and attentive.

As EXPERT 3 and 4 point out, not only speaking proactively but also acting proactively is valuable in some situations. It can be pleasant for the user if the VA learns about his preferences and does things that he normally wants the VA to do automatically after a few times. However, EXPERT 1 and 2 make clear that the VA has to be aware of the context and the user's individual preferences to decide whether a proactive utterance or action is appropriate in a certain situation because proactivity can also annoy or distract the user. According to EXPERT 6, it makes sense to learn from the feedback the user gives to detect the contents and situations in which the user is open for proactive behavior.

4.2.9. Context Awareness. According to PEARL, " $[0]$ ne reason many virtual assistants $[\ldots]$ currently struggle with conversational UI is because they lack context" [18]. All the experts agree that to behave appropriately, the VA not only has to be aware of the situational context but also has to remember things about the user and the interaction with him from previous conversations. EXPERT 6 submits that designers have to take care that the VA does not bring up something in the conversation that it talked about with the user a few weeks ago and that a human would not be able to remember anymore. Such a good memory is not humanlike and will probably appear creepy. Designers have to define after which period of time a VA should not refer to a certain memory again towards the user.

\section{Limitations and Future Work}

Designers can easily use the developed guidelines, if they seek advice for their own projects in the field of VAs, because they are rather generic and give a clearly structured overview. Because of their generality, it has to be considered that the guidelines might not propose the best option for design in every case. In addition to that, the guidelines have a narrow scope in only two phases of the design process and do not assert the claim to cover all the possibilities for the design.

Besides of the implications for practice, this research closes a research gap by delivering guidelines for the representational and interaction design of in-vehicle VAs. 
Table 4: Design guidelines for interaction design: Appropriate behavior

\begin{tabular}{|c|c|c|c|}
\hline $\begin{array}{l}\text { Assistant } \\
\text { requirements }\end{array}$ & $\begin{array}{l}\text { Supporting } \\
\text { literature }\end{array}$ & Design guidelines for in-vehicle VAs & Experts \\
\hline \multirow{4}{*}{$\begin{array}{l}\text { 12. An in-vehicle } \\
\text { VA has to have } \\
\text { the ability to } \\
\text { recognize, } \\
\text { understand and } \\
\text { react } \\
\text { appropriately to } \\
\text { emotions. }\end{array}$} & \multirow{4}{*}{$\begin{array}{l}\text { PEARL } \\
\text { [18:146] } \\
\text { HASSENZAHL } \\
\text { ET AL. } \\
\text { [8:531] } \\
\text { NASS ET AL. } \\
\text { [15:1973] } \\
\text { NOGA ET AL. } \\
\text { [17] }\end{array}$} & $\begin{array}{l}\text { 12.1. Recognize the user's emotions by analyzing gestures, facial } \\
\text { expressions, text, tone of voice and physiological signs of mood } \\
\text { such as heart rate or skin changes. }\end{array}$ & E 1,5 \\
\hline & & $\begin{array}{l}\text { 12.2. Tailor the VA's communication style and the content of } \\
\text { what it says to the user's mood and to possible pains in the } \\
\text { current situation. }\end{array}$ & E 1 \\
\hline & & $\begin{array}{l}\text { 12.3. Preset how emotional the VA should be in general but allow } \\
\text { flexible adjustment in some extent based on the user's } \\
\text { preferences, his mood and the current situation. }\end{array}$ & E 6 \\
\hline & & $\begin{array}{l}\text { 12.4. Take care that the VA still focuses on assisting the user } \\
\text { so that it does not react emotionally if it is inappropriate, } \\
\text { ridiculous or strange. }\end{array}$ & E 1-4 \\
\hline \multirow{4}{*}{$\begin{array}{l}\text { 13. An in-vehicle } \\
\text { VA has to figure } \\
\text { out the right } \\
\text { situation for } \\
\text { proactive } \\
\text { behavior. }\end{array}$} & & $\begin{array}{l}\text { 13.1. Use proactive behavior to make the user's life easier, } \\
\text { prevent him from unpleasant situations or improve his } \\
\text { driving safety. }\end{array}$ & E $2-5$ \\
\hline & & $\begin{array}{l}\text { 13.2. Learn from the user's preferences and habits to let the VA } \\
\text { do things automatically. }\end{array}$ & E 2,4 \\
\hline & & $\begin{array}{l}\text { 13.3. Be aware of the context and the user's individual preference } \\
\text { to decide when and how to say or do something proactively. }\end{array}$ & E $1-2$ \\
\hline & & $\begin{array}{l}\text { 13.4. Learn from the feedback the user gives to detect the } \\
\text { contents and situations in which the user is open for proactive } \\
\text { behavior. }\end{array}$ & E 6 \\
\hline \multirow{3}{*}{$\begin{array}{l}\text { 14. An in-vehicle } \\
\text { VA has to be } \\
\text { aware of the } \\
\text { context. }\end{array}$} & \multirow[t]{3}{*}{$\begin{array}{l}\text { PEARL } \\
{[18: 153]}\end{array}$} & $\begin{array}{l}\text { 14.1. Take care that the VA is aware of the situational context } \\
\text { to be able to behave appropriately within the interaction with } \\
\text { the user. }\end{array}$ & E $1-5$ \\
\hline & & $\begin{array}{l}\text { 14.2. Let the VA memorize things about the user and the } \\
\text { interaction with him from previous conversations } \\
\text { (preferences, behavior patterns). }\end{array}$ & E $1-5$ \\
\hline & & $\begin{array}{l}\text { 14.3. Take care that the VA will not bring up or refer to } \\
\text { something they talked about a few weeks ago that a human would } \\
\text { not remember. }\end{array}$ & E 6 \\
\hline
\end{tabular}

Further guidelines for other phases and activities during the design process still need to be developed which is suggested as a topic for future research. As the guidelines are developed using a qualitative approach, we may conduct a quantitative survey for a triangulation of the results and further refinement and evaluation of the proposed guidelines. In addition to that, a following step after this research is testing the developed guidelines by applying them to a real project that deals with the design and development of an in-vehicle VA. In section 4.2.5 the topic of trust is mentioned by one of the Experts. This topic was especially identified for further examination in future work. Moreover we want to further emphasize the invehicle context of the user, meaning adapting the behavior of the VA depending on wether the user is driving or not. According to the DSR methodology, applying the artifact to a case study is one of the recommended methods for the demonstration [19]. The findings from the utilization of the guidelines in practice can then be used to evaluate and revise the artifact again.

\section{Conclusion}

This research yields guidelines for the representational and interaction design of virtual invehicle assistants to provide a convincing UX. The guidelines focus on the aim to provide a convincing UX to ensure that it is valuable for people to use the in-vehicle VA and that it makes their lives easier. The focus on the UX results from the approach of this research: The guidelines are based on requirements to provide a convincing UX with an in-vehicle VA derived from the previous research literature and the results of five interviews with experts specialized in 
designing and developing speech assistants. If designers consider all the design guidelines during representational and interaction design, the developed in-vehicle VA would meet all the requirements for a convincing UX.

\section{References}

[1] Bengler, K., K. Dietmayer, B. Farber, M. Maurer, C. Stiller, and H. Winner, "Three decades of driver assistance systems: Review and future perspectives", IEEE Intelligent Transportation Systems Magazine 6(4), 2014, pp. 6-22.

[2] Benyon, D., Designing Interactive Systems. A comprehensive guide to HCI, UX and interaction design, Pearson Education Limited, Edinburgh, 2014.

[3] Cohen, M.H., J.P. Giangola, and J. Balogh, Voice User Interface Design, Addison-Wesley, Boston, 2004.

[4] Cramer, H., and J. Thom, "Moving Parts surrounding Conversational UX", Position Paper Conversational UX Design CHI 2017 Workshop, 2017.

[5] Giangola, J., and P. Cao, "Conversation Design: Speaking the Same Language", Google Design, 2017. https://design.google/library/conversation-design-speakingsame-language/

[6] Guzman, A.L., "Making AI Safe for Humans: A Conversation with Siri", In R.W. Gehl and M. Bakardjieva, eds., Socialbots and their Friends. Digital Media and the automation of Sociality. Taylor \& Francis, New York, 2017, 69-85.

[7] Hassenzahl, M., "The Thing and I: Understanding the Relationship Between User and Product", In M.A. Blythe, K. Overbeeke, A.F. Monk and P.C. Wright, eds., Funology. From Usability to Enjoyment. Human-Computer Interaction Series. Springer, Dordrecht, 2004, 31-42.

[8] Hassenzahl, M., A. Wiklund-Engblom, A. Bengs, S. Hägglund, and S. Diefenbach, "Experience-Oriented and Product-Oriented Evaluation: Psychological Need Fulfillment, Positive Affect, and Product Perception", International Journal of Human-Computer Interaction, 2015, pp. 530-544.

[9] McTear, M.F., Z. Callejas, and D. Griol, The Conversational Interface: Talking to Smart Devices, Springer International Publishing Switzerland, Cham, 2016.

[10] Meuser, M., and U. Nagel, "The Expert Interview and Changes in Knowledge Production”, In A. Bogner, B. Littig and W. Menz, eds., Interviewing Experts. Palgrave Macmillan, Hampshire, 2009, 17-42.

[11] Miles, M.B., A.M. Hubermann, and J. Saldaña, Qualitative Data Analysis: A Methods Sourcebook, Sage, Arizona State University, USA, 2014.

[12] Moore, R.J., R. Arar, G.-J. Ren, and M.H. Szymanski, "Conversational UX Design", Position Paper Conversational UX Design CHI 2017 Workshop, 2017.

[13] Morana, S., C. Friemel, U. Gnewuch, A. Maedche, and J. Pfeiffer, "Interaktion mit smarten Systemen — Aktueller
Stand und zukünftige Entwicklungen im Bereich der Nutzerassistenz", Wirtschaftsinformatik \& Management 9(5), 2017, pp. 42-51.

[14] Mori, M., "The Uncanny Valley: The Original Essay by Masahiro Mori”, IEEE Spectrum: Technology,

Engineering, and Science News, 2012.

https://spectrum.ieee.org/automaton/robotics/humanoids/th e-uncanny-valley

[15] Nass, C., I.-M. Jonsson, H. Harris, et al., "Improving Automotive Safety by Pairing Driver Emotion and Car Voice Emotion", Extended Abstracts of Human Factors in Computing Systems: CHI 2005, USA, 2005, pp. 1973-1976.

[16] Nielsen, J., "10 Heuristics for User Interface Design: Article by Jakob Nielsen”, Nielsen Norman Group, 1995. https://www.nngroup.com/articles/ten-usability-heuristics/

[17] Noga, M., C. Saravana, and S. Overby, "Empathy: The Killer App for Artificial Intelligence”, Digitalist Magazine by $S A P, 2017$. http://www.digitalistmag.com/executiveresearch/empathy-the-killer-app-for-artificial-intelligence

[18] Pearl, C., Designing Voice User Interfaces: Principles of Conversational Experiences, O’Reilly, Sebastopol, 2016.

[19] Peffers, K., T. Tuunanen, M.A. Rothenberger, and S. Chatterjee, "A Design Science Research Methodology for Information Systems Research", Journal of Management Information Systems Vol. 24(No. 3), 2007, pp. 45-77.

[20] Rogers, Y., H. Sharp, and J. Preece, Interaction Design: beyond human-computer interaction, Wiley, Chichester, West Sussex, 2011.

[21] Schmitt, B.H., Experiential Marketing: How to get Customers to Sense, Feel, Think, Act, Relate: To Get Customers to Relate to Your Brand, Free Press, New York, 1999.

[22] Seeber, I., E. Bittner, R.O. Briggs, et al., "Machines as Teammates: A Collaboration Research Agenda", Proceedings of the 51st Hawaii International Conference on System Sciences, (2018).

[23] Skalski, P., and R. Tamborini, "The Role of Social Presence in Interactive Agent-Based Persuasion", Media Psychology 2007(10), 2007, pp. 385-413.

[24] Wallach, D., J. Conrad, and T. Steimle, "The UX Metrics Table: A Missing Artifact", In A. Marcus and W. Wang, eds., Design, User Experience, and Usability: Theory, Methodology, and Management. DUXU 2017. Lecture Notes in Computer Science. Springer, Cham, 2017, 507-517.

[25] Zhao, S., "Humanoid social robots as a medium of communication", New Media \& Society 8(3), 2006, pp. 401-419.

[26] Zhou, H., and X. Fu, "Understanding, Measureing, and Designing User Experience: The Causal Relationship Between the Aesthetic Quality of Products and User Affect", In J.A. Jacko, ed., Human-Computer Interaction: Interaction Design and Usability. 12th International Conference, HCI International 2007, Part 1. Springer, Berlin, Heidelberg, 2007, 340-349. 